Paulo André Niederle*

Doutorando de Ciências Sociais em Desenvolvimento, Agricultura e Sociedade/UFRRJ.E-mail: pauloufpel@yahoo.com.br

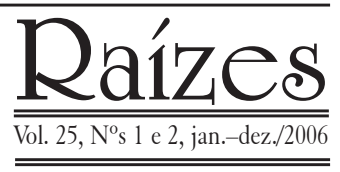

Trabalho recebido em:

$16 / 12 / 2005$

Aprovado para publicação em:

23/03/2007

\title{
MERCANTILIZAÇÃO, DIVERSIDADE E ESTILOS DE AGRICULTURA
}

\section{RESUMO}

O artigo discute o processo de mercantilização da agricultura, ressaltando o modo parcial e multifacetado como este afeta um conjunto de domínios essenciais à reprodução das formas familiares de produção. Destaca, ainda, a relação entre a mercantilização diferencial e a constituição de distintos estilos de agricultura, apresentando esta noção como uma alternativa analítica à compreensão da diversidade que marca o mundo rural contemporâneo.

Palavras-chave: agricultura familiar, mercados, desenvolvimento rural

\section{COMMODITIZATION, DIVERSITY AND FARMING STYLES}

\section{ABSTRACT}

This paper discuss the commoditization of agriculture, pointing out the partial and multifaceted way in which this process affects a set of essential dimensions of reproduction of the forms of production. It discusses also the relation between the differential commoditization and the constitution of distinct farming styles, presenting this notion as an analytical approach to understanding the diversity that marks the agricultural contemporary world.

Key words: family farm, markets, rural development

\footnotetext{
* O autor agradece os comentários de Sergio Schneider, Catia Grisa e pareceristas anônimos da revista Raízes, eximindo-os, no entanto, de qualquer responsabilidade por eventuais imprecisões ou omissões.
} 


\section{INTRODUÇÃO}

A consolidação de perspectivas teóricas que visam compreender o mundo rural de forma mais ampla e complexa do que o dualismo reducionista que marca as orientações neoclássicas tem propiciado avanços significativos na identificação da diversidade e multiplicidade de formas e processos sociais presentes na agricultura. No meio acadêmico, isto tem resultado na proliferação de novos temas na agenda de pesquisa social e, nas instituições de $\mathrm{P} \& \mathrm{D}$, tem gerado discussões acerca das distintas trajetórias que segue o desenvolvimento rural.

Inserindo-se em um esforço de apresentar abordagens teóricas alternativas à compreensão da heterogeneidade dos processos de reestruturação capitalista na agricultura, este artigo discute a forma com que a crescente mercantilização da agricultura relaciona-se à emergência de distintos estilos de agricultura. Ao mesmo tempo, destaca como isto ocorre em consonância com trajetórias de desenvolvimento desigual, elucidando a heterogeneidade entre os agricultores, a integração de alguns em contrapartida da exclusão de outros e a conformação de distintas dinâmicas sócio-econômicas.

Parte-se do pressuposto de que o desenvolvimento da agricultura esteve relacionado a uma profunda transformação de sua base técnica que foi responsável por tornar o mercado o principal mecanismo regulador dos processos produtivos e da vida no meio rural. Segundo aludiram alguns autores, a magnitude destas transformações levaria à situação identificada por Polanyi (1980) em que "em vez de a economia estar embutida nas relações sociais, são as relações sociais que estão embutidas no sistema econômico". Todavia, mesmo após a tão propalada solidificação da chamada "economia de mercado", a inserção em diversos circuitos mercantis continua condicionada por fatores não estritamente econômicos, sinal de que a mercantilização não consegue alcançar seu limite extremo.

A mercantilização sugerida pela dependência dos agricultores aos mercados é condicionada por uma complexa relação em que o contexto externo imprime uma dinâmica a partir da qual os agricultores negociam a inserção em diferentes circuitos de troca, tendo em vista suas próprias condições e os interesses dos demais atores. As formas como os agricultores reagem ao ambiente e assimilam as transformações propostas pela gramática sustentada pelo regime prevalecente de mercantilização dos espaços rurais, lhes permitem alterar este processo e, fundamentalmente, sustentar relações fortemente balizadas por valores determinados por elementos não mercantis.

$\mathrm{Na}$ seqüência são analisadas algumas questões relacionadas à mercantilização desenvolvidas no âmbito da sociologia da agricultura pelo "enfoque da produção simples de mercadorias" a partir dos trabalhos de Friedmann (1978) e Bernstein (1979). A seção subseqüente apresenta algumas críticas a este referencial articuladas por Ploeg (1990) e Long (1986) a partir de uma perspectiva orientada aos atores e da idéia de mercantilização diferencial. Outra seção discute como a mercantilização da agricultura pode ser compreendida de modo mais amplo do que simplesmente relacionada ao trabalho e à produção agrícolas, isto é, como um amplo processo social está associado à idéia de mercado enquanto instituição social. Nas duas últimas seções, demonstra-se como este processo parcial e multifacetado vincula-se à formação de distintos estilos de agricultura (Ploeg, 1990, 1993; Vanclay et al., 2006), procurando elucidar a diversidade de formas de agricultura encontrada no mundo rural contemporâneo.

\section{A PRODUÇÃO SIMPLES DE MERCADORIAS E O DEBATE DA MERCANTILIZAÇÃO}

A sociologia da agricultura constitui uma das principais correntes de pensamento nos estudos rurais contemporâneos, representando, desde meados da década de 70, um conjunto de "perspectivas críticas" que alcançaram status teórico e metodológico para tornar-se a principal expressão de oposição aos pressupostos da rural sociology e ao funcionalismo nos estudos agrários (Buttel et al., 1991; Schneider, 1997). Sem um arcabouço teórico bem delimitado e marcada por uma ampla diversidade teórica, sua unidade deve-se às novas proposições para os estudos agrários nos quais estão a prioridade às questões estruturais e um "interesse em examinar os processos pelos quais o capitalismo penetra à economia rural e reestrutura a vida sócio-econômica” (Long, 1986).

Nesta perspectiva, diversos autores têm focalizado as relações sociais de produção na agricultura e a construção de um referencial analítico capaz de explicar a persistência das formas familiares de produção nas sociedades capitalistas avançadas. Dentre os temas centrais ao debate, a relação dos agricultores com os mercados desponta como um dos mais controversos. A constituição do que Long et al. (1986) denominaram de "o debate da mercantilização" surge, assim, relacionada ao interesse 
analítico de encontrar uma solução ao impasse marxista da manutenção das formas familiares de produção e da generalização das relações mercantis.

As primeiras e mais reconhecidas alternativas constituídas, neste sentido, permaneceram significativamente ligadas ao referencial marxista clássico, porém apoiadas na noção de "produção simples de mercadoria" ou "pequena produção de mercadorias". ${ }^{1}$ Esta noção foi utilizada por Marx (1982) para caracterizar formas pré-capitalistas não completamente inseridas nos processos de reprodução ampliada, o que seria fruto de uma integração parcial à divisão social do trabalho. Formas estas que, segundo este autor, seriam suplantadas pelo próprio desenvolvimento do capitalismo.

Criticando Marx por utilizar esta noção de modo excessivamente abstrato, Friedmann (1978) procura justificar a persistência de unidades familiares de produção nas sociedades contemporâneas, conciliando, a esta perspectiva categorias específicas do referencial chayanoviano, sobretudo, a partir da inclusão de variáveis como o ciclo demográfico e as relações de parentesco. Embora isto não tenha resultado na adoção da idéia de campesinato, esta inovação teórica procurou na especificidade de relações sociais, vistas por Chayanov (1974), elementos para diferenciar os produtores simples de mercadorias das unidades essencialmente capitalistas:

\footnotetext{
Na produção simples de mercadorias, a propriedade da empresa e a provisão de trabalho estão combinadas na unidade familiar. Como resultado, existe somente uma classe diretamente envolvida na produção e na distribuição do produto. Produção e consumo são organizados através de parentesco (kinship) ao invés de relações de mercado. A unidade familiar compra os meios de produção, coloca-os em movimento com seu próprio trabalho, e se apropria do produto final. O último é vendido para renovar todos os elementos do processo produtivo, o qual consiste exclusivamente do consumo produtivo e pessoal. A condição básica para a reprodução simples, além disso, é a re-criação continuada da integridade da unidade familiar como unidade de consumo produtivo e pessoal (Friedmann, 1978a).
}

$\mathrm{Na}$ forma social de produção identificada por Friedmann (1978a) o agricultor vende a mercadoria produzida com o seu trabalho e consegue dinheiro para repor o estritamente necessário para renovar o processo produtivo, do que consta inclusive reproduzir a força de trabalho, no caso, comprar os meios de vida indispensáveis a sua família. Segundo a autora, uma vez que não há expropriação direta e excedente, esta forma de produção apresentase completamente diferente da produção capitalista.

De todo modo, o que mais interessa aqui é perceber que para a autora o fato de a produção e a reprodução serem organizadas, de acordo com relações sociais específicas, e não diretamente em virtude das condições de mercado, não significa que exista autonomia em relação a este. Pelo contrário, segundo a autora, as relações sociais e técnicas que se estabelecem na produção simples requerem "condições de mercados completamente desenvolvidos, não somente para as mercadorias produzidas pelo trabalho familiar, mas também para terra, meios de produção, artigos de consumo pessoal, dinheiro e, mais importante, a própria força de trabalho" (Friedmann, 1978). O objetivo é excluir qualquer interferência de fatores extra-mercantis na circulação de mercadorias, o que também pressupõe uma economia completamente monetizada.

De acordo com Bernstein (1986), esse modelo sugere a completa integração aos mercados, o que, juntamente com as diferentes relações de trabalho, distingue produtores simples de mercadorias de produtores domésticos e empresários capitalistas. Além disso, representa estágios diferenciados de uma seqüência evolucionista de desenvolvimento: "produção doméstica (nenhuma ou parcial integração aos mercados + trabalho familiar) $>$ produção simples de mercadorias (completa integração aos mercados + trabalho familiar) > capitalista (completa integração aos mercados + trabalho assalariado)" (Bernstein, 1986).

Ainda segundo Bernstein (1979), os produtores domésticos se transformam em pequenos produtores de mercadorias em decorrência das condições do ambiente externo, ou seja, do nível de desenvolvimento da economia nacional, o qual determina as relações entre capital e trabalho. Sustenta que, uma vez que os pequenos produtores sistematicamente produzem mercadorias, eles são totalmente controlados pelos mercados, só assumindo que o processo de mercantilização não é uniforme nem completo, em virtude do desenvolvimento capitalista ainda não ter conseguido solapar a "economia natural" em todos os locais.

Já a oposição entre unidades domésticas e produtores

1 As discussões dos principais autores desta perspectiva podem ser acompanhadas em diversos números do Journal of Peasants Studies que, durante muitos anos, foi editado por Henry Bernstein. Além disso, uma ampla revisão pode ser feita no número especial do Journal of Cultural and Social Practice, n.20, dec. 1986 (Rethinking Petty Ccommodity Production) editado por Alison MacEwen Scott. 
simples de mercadorias reside na especialização e competitividade. Enquanto aquelas produzem uma diversidade de artigos para consumo direto e meios de produção, bem como excedente para venda, estes são essencialmente especializados e inseridas em mercados competitivos. Segundo Friedmann (1978), "quando a produção doméstica é especializada e competitiva e os meios de produção e subsistência devem ser comprados, isto é produção simples de mercadorias". Este tipo de construção desconsidera formas de produção relativamente especializadas, mas que mantém considerável utilização de recursos não mobilizados nos circuitos mercantis, o que sugere uma inserção parcial aos mercados.

De modo genérico, podem-se sintetizar as conclusões contidas nos textos de Friedmann e Bernstein como uma tentativa de demonstrar que a passagem de uma forma de produção (produção doméstica) para outra (produção simples de mercadorias) envolve a completa inserção nos mercados, o que reflete ainda um processo inevitável e unidirecional do desenvolvimento das relações sociais de produção capitalistas. Além disso, este enfoque tem se caracterizado por manter uma compressão dos mercados enquanto estruturas rígidas e externas aos atores, os quais viram reflexos de sistemas totalizantes.

\section{MERCANTILIZAÇÃO DIFERENCIAL: AS CONTRIBUIÇÕES DA ESCOLA DE WAGENINGEN}

Estabelecendo um profícuo debate com a perspectiva acima apresentada, alguns trabalhos desenvolvidos na Wageningen University (Holanda), em especial de Norman Long e Jan Douwe van der Ploeg, têm sustentado que este enfoque da produção simples de mercadorias associa-se à reprodução de análises teóricas que excluem a capacidade dos atores sociais de intervir no curso do desenvolvimento, subtraindo seus poderes de agência para criar condições de reprodução em face às tendências homogeneizadoras do capitalismo. Neste sentido, argumentam que semelhantes teses carregam consigo a pretensão de constituir uma análise dialética, mas não passam de visões lineares das mudanças, tomadas como exclusivamente dependentes das condições do desenvolvimento capitalista.

De acordo com Ploeg (2003), o fato de os agricultores mobilizarem uma ampla gama de recursos fora dos mercados reflete em "espaços de manobra" e estratégias criadas para manter uma autonomia relativa da unidade de produção. Neste sentido, é equivocada tanto a percepção de que a mercantilização induz à perda total da autonomia, quanto de que este processo possa ser completo, uma vez que persiste um amplo conjunto de recursos mobilizados fora dos circuitos mercantis.

Assim, são re-conceituadas as categorias analíticas que sustentam o enfoque da produção simples de mercadorias. O resultado é a conexão de um conjunto teórico neomarxista com categorias chayanovianas específicas e, mormente, com uma "perspectiva orientada aos atores" (Long, 2001; Ploeg, 1993). De maneira especial, altera-se a compreensão dos mercados, que passam a ser vistos como estruturas resultantes das múltiplas redes de relações estabelecidas entre os agricultores, uma série de outros atores sociais e uma gama de recursos materiais. Desfaz-se o caráter fixo ou mecânico das estruturas e, nos termos em que opera o debate, a noção de mercados enquanto "explanans", isto é, elementos genéricos que regem a ação social (Long, 2001). Isto leva a uma compreensão diferenciada dos mercados, a qual sustenta que, ao mesmo tempo em que constituem mecanismos responsáveis pela transformação de valores de uso em valores de troca que estabelecem a forma social da mercadoria (como é definida a mercantilização no escopo do pensamento marxiano), são instituições sociais que refletem disputas de poder, convicções e valores. Igualmente, compõem um conjunto de regras que imputam limites e possibilidades às ações dos agentes (Abramovay, 2001).

A mercantilização torna-se, então, o resultado de relações sociais que expressam a luta entre diferentes atores pelo controle de recursos e processos. Destarte, não há razão em falar de mercantilização a partir do nível de desenvolvimento dos mercados como se este fosse alheio à ação social. Se for correto que a mercantilização reflete a pressão que as estruturas de mercado exercem sobre os atores, também é certo que ela pode representar uma estratégia deliberada destes. Por conseguinte, a extensão da mercantilização da agricultura passa a ser o resultado direto da luta entre o capital, o Estado e os agricultores, em que a disputa central envolve o controle dos principais recursos utilizados nos processos reprodutivos e, desta forma, o domínio dos próprios mercados.

Esta dialética do controle envolve um processo de 'externalização' que faz referência ao acesso assimétrico aos recursos necessários ao fluxo dos processos reprodutivos das unidades familiares. Destaca-se, neste sentido, o domínio que agentes externos às unidades familiares exercem sobre insumos e fatores de produção que são mobili- 
zados nos mercados, o que lhes permite influenciar diretamente o comportamento dos agricultores. $\mathrm{O}$ resultado mais evidente desta externalização é a gradativa separação entre o trabalho mental e o trabalho manual e a perda do controle direto sobre as condições nas quais se executam os processos de produção. Configuram-se, então, novos parâmetros sobre os quais os membros da unidade de produção planejam e executam seus projetos, articulados entre si e mediados por uma estrutura ou contexto que determina os parâmetros sociais e econômicos relevantes. Deste modo, a externalização é responsável por profundas alterações nos processos mais significativos de reprodução da unidade familiar.

Conectados à mercantilização, Ploeg $(1990 ; 2006)$ e Long (2001) destacam, ainda, a existência de uma ampla incorporação institucional dos agricultores, em que, junto à crescente externalização, desenvolvem-se processos de "cientificação" (produção de tecnologias que aumentam o controle de atores externos - empresas, bancos, Estado etc. - sobre o processo de trabalho agrícola e sobre a natureza) e "centralização estatal” (coordenação estatal das inter-relações entre várias instituições e atores para resolução de conflitos) que favorecem a dependência dos agricultores.

Não obstante, nesta perspectiva tem se destacado a capacidade dos agricultores de desenvolverem uma série de estratégias para modificar, neutralizar, resistir e, por vezes, até acelerar os resultados destes processos de acordo com sua própria condição social e econômica. Trata-se de uma dinâmica não linear, com avanços e reveses e, fundamentalmente, expressa na inserção diferencial das unidades familiares aos mercados.

\section{A MERCANTILIZAÇÃO COMO UM AMPLO PROCESSO SOCIAL}

A análise de Ploeg $(1990 ; 1992)$ centra-se, fundamentalmente, sobre as relações de trabalho e produção no interior das unidades familiares. Por conseguinte, o autor retoma a definição de mercantilização focalizando os micro-processos aí enraizados, para delimitar a existência de distintos "graus de mercantilização". Estes são, por ele, operacionalizados pelo cálculo da proporção entre a quantidade de mercadorias mobilizadas pelos agricultores nos diversos circuitos mercantis e os valores de uso reproduzidos no ciclo de produção anterior interno à unidade de produção (Ploeg, 1990) ${ }^{2}$.

Como o leitor pode notar, analogamente à maior parte dos estudos da sociologia da agricultura, Ploeg mantém seu conjunto de conceitos operacionais primordialmente alicerçados em variáveis de ordem econômico-produtivas, tais como o trabalho contratado, crédito, terra, alimentos e insumos. Isto lhe dificultou ampliar a noção de mercantilização para outros domínios. Seu principal mérito foi compreender a heterogeneidade de processos produtivos associados à mercantilização, demonstrando que esta se constitui do resultado da negociação entre os agricultores e outros atores sociais. A despeito disto, o autor pouco adentra ao processo de mercantilização presente para além dos modus operandi agrícolas, ou seja, à relação mais ampla, da mercantilização com a ruralidade. Desta forma, em que pese as possibilidades que sua operacionalização trouxe em termos de quantificação do fenômeno, a análise tornou-se limitada em termos da possibilidade de perceber a mercantilização de forma mais ampla, o que também poderia levar a uma compreensão mais apurada dos mercados enquanto instituições sociais.

Como faz questão de destacar Marsden (1995), a mercantilização constitui um processo mais diverso que se estende a outras dimensões da vida social. Nos seus termos, trata-se de

[...] um amplo processo social e político pelo qual os valores mercantis são construídos e atribuídos a objetos rurais e agrícolas, artefatos e pessoas. Ela não representa um processo único e universal que transforma apenas o trabalho na agricultura (tal como sugerido na literatura marxista sobre o desenvolvimento agrário). Trata-se, ao contrário, de um fenômeno diversamente construído, em torno do qual os processos de desenvolvimento coalescem e se generalizam.

Um amplo processo social que adentra as mais distintas esferas de relações sociais, atribuindo às interações humanas e materiais que ali se reproduzem valores mercantis que passam a regular as práticas sociais dos agricultores. É neste sentido que Marsden (1995) destaca como vários espaços rurais não essencialmente produtivos têm sido mercantilizados, como é o caso associado a algumas das novas funções desempenhadas pelo meio ru-

Disto procede que a definição de mercadoria é produto de relações sociais específicas encontradas no mercado e não, como é sugerido por Vandergest (1988), pela sua produção ter sido racionalmente conduzida com o objetivo de comercialização, neste caso pensando a mercantilização em termos de uma contínua "penetração da calculabilidade de valor de troca pelos produtores". 
ral. Estas representam, por exemplo, um conjunto de bens materiais e simbólicos como a paisagem, o folclore e a gastronomia locais, aos quais os agricultores passam a atribuir valor de troca em virtude da venda aos consumidores urbanos.

Navarro (2002) destaca que além de conformar novas formas de trabalho e produção, a mercantilização foi responsável por criar uma "nova atmosfera" de relações sociais, culturais e simbólicas, gradualmente materializada em uma nova sociabilidade. Com efeito, é a partir destas transformações nas relações sociais que se pode apreender como a mercantilização modifica um leque variado de noções estratégicas, valores e percepções que guiam os agricultores na construção de distintos estilos de agricultura.

Além disso, na conjunção dos distintos significados que este fenômeno comporta, percebe-se como os mercados, mais do que simples mecanismos de transformação de valores de uso em valores de troca, são instituições sociais que refletem a contínua interação entre os atores, seus projetos, estratégias e repertórios culturais, são instituições envolvidas no amplo processo de constituição de uma nova atmosfera de relações sociais.

\section{ESTILOS DE AGRICULTURA: EXPRESSÕES DA DIVERSIDADE NO MEIO RURAL}

A mercantilização não traz consigo efeitos que podem ser apreendidos genericamente, isto é, desconsiderando como outros fatores podem influenciar diretamente seu curso. Neste caso, a noção de diversidade emerge como símbolo das desuniformidades que caracterizam este processo. Não obstante, é necessário criar meios de apreender esta diversidade e, neste sentido, sustenta-se aqui que a abordagem dos "estilos de agricultura" desenvolvida por Ploeg (1994; 2003) pode ser uma forma promissora para analisá-la sem incorrer às totalizações que encobrem as heterogeneidades internas das unidades familiares ou, aos individualismos para os quais, no limite, cada uma delas precisaria ser estudada como se representasse um universo ímpar e distinto de relações sociais.

Esta abordagem tem se constituído como importante ferramenta analítica em uma ampla gama de estudos rurais europeus. A noção originariamente desenvolvida por
Hofstee (1946) em The Causes of Diversity in Dutch Agriculture (Ploeg, 1993) foi retomada por Ploeg notadamente a partir da década de 1990, tornando-se um approach para a compreensão de elementos da diversidade da agricultura. Sua proliferação fez, todavia, com que surgissem várias reformulações à definição inicial, formatando um conceito definido e ilustrado desde vários pontos de vista (Ploeg, 1993) ${ }^{3}$.

Segundo Ploeg (1994), inicialmente a noção de estilos de agricultura esteve articulada às dimensões da cultura e localidade, representando "um complexo e integrado conjunto de noções, normas, conhecimentos e experiências portados por um grupo de agricultores em uma região específica que descreve o modo com que a farming práxis é levada adiante". Com efeito, a construção inicial faz referência às diferenças inter-regionais da agricultura européia, porém, à medida que se torna evidente a heterogeneidade no seio de uma mesma comunidade, estilos de agricultura tornaram-se principalmente um fenômeno intra-regional sendo referidos, fundamentalmente, em relação às distintas lógicas produtivas das unidades familiares, em uma perspectiva mais diretamente orientada aos atores, seus projetos e estratégias (Ploeg, 2003).

Não obstante, a noção apresenta-se com diversas faces no conjunto dos estudos de Ploeg. Nos primeiros textos, em que o leitor se depara com um conceito ainda nascente, este aparece conectado ao processo produtivo agrícola: "estilos de agricultura (ou uso do solo), pode ser definido como uma estrutura válida de relações entre produtores, objetos de trabalho e meios, (...), é o produto de uma estruturação específica do trabalho agrícola" (Ploeg, 1990). No artigo publicado em 1993, aproxima-se da definição original de Hofstee propondo que

Estilo de agricultura refere-se a um repertório cultural, uma composição de idéias normativas e estratégicas sobre como a agricultura (farming) será feita. Um estilo envolve um modo especifico de organização da empresa agrícola: prática agrícola e desenvolvimento são definidos pelo repertório cultural, o qual por sua vez é testado, afirmado e, se necessário, ajustado pela prática. Por conseguinte, um estilo de agricultura é uma forma concreta da práxis, uma unidade particular de pensamento e ação, de teoria e prática (Ploeg, 1993).

Dois anos depois, acrescentam-se ao conceito elemen-

Não será desenvolvida aqui uma análise das divergências teóricas e metodológicas entre autores em relação à noção de estilos de agricultura. O artigo de Vanclay et al. (2006) caminha nesta direção e oferece ao leitor suas posições sobre as principais questões que estão em discussão atualmente. 
tos que se referem a: a) um conjunto de noções estratégicas, valores e percepções que um grupo particular de agricultores utiliza para organizar sua unidade de produção em um determinado caminho; b) uma estruturação específica da prática agrícola que corresponde a uma noção estratégica de repertório cultural e; c) um conjunto determinado de inter-relações entre a empresa agrícola e os mercados (Ploeg, 1995). Desde então estes três componentes (normas, práticas e relações com os mercados) têm estado presentes em suas definições (Howden \& Vanclay, 2000).

Portanto, o conceito assume um caráter multidimensional, sendo concebido de diversas maneiras a partir do "ponto de entrada" do pesquisador. Assim sendo, Vanclay et al., (2006) sustentam a possibilidade de perceber estilos de agricultura como "um conjunto de estratégias para a agricultura (cursos de ação para sobreviver) onde uma estratégia refere-se a um conjunto de guias práticos e/ou racionalidades para tomar decisões de acordo com uma situação particular”. Assim, estilos e estratégias se relacionam a uma espécie de lógica reprodutiva, a qual pode ser investigada em termos de um calculus, isto é, de um discurso prático. ${ }^{4}$

Este cálculus representa uma lógica prática condicionada por relações sociais particulares (Ploeg 2003). Portanto, não se trata de um ator isento de constrições estruturais: "estilos são criados não somente através de dinâmicas sócio-culturais, mas também como resposta a forças estruturais “ diferentes estilos existem para diferentes situações de mercado dos diferentes agricultores" (Vanclay et al., 2006). Trata-se de um "raciocínio estratégico" capaz de construir diferentes perspectivas a partir das quais os agricultores organizam suas relações sociais (Ploeg, 1994).

Tendo isto em vista, Ploeg (1990) demonstra que as unidades familiares organizam-se segundo duas lógicas ou vias históricas. A primeira representa uma espécie de "reprodução relativamente autônoma ou historicamente garantida" em que força de trabalho, objetos e meios necessários para cada ciclo de produção são resultados do ciclo precedente. No outro extremo, uma "reprodução dependente do mercado" em que estes e outros recursos são mobilizados pela via dos mercados.
Mas as diferenças entre estas duas formas adentram a outras dimensões. Em termos de eficiência técnica do trabalho, por exemplo, a reprodução autônoma desenvolvese a partir de crescente intensificação do trabalho, para o que existe uma vinculação dos processos de produção e reprodução à qualidade do trabalho, proporcionando assim rendimentos crescentes por objeto de trabalho. Já a reprodução dependente do mercado se desenvolve pela ampliação da escala, na qual o número de objetos de trabalho por produtor aumenta enquanto os rendimentos caem continuamente (Ploeg, 1992).

A partir destas diferenciações Ploeg (1990) tipifica os produtores de leite da Emilia Romagna (Itália) em I-farmers (que optam pela intensificação) e E-farmers (ampliação de escala e relativa extensificação), demonstrando que, em ambas as vias, mercantilização, externalização e institucionalização se desenvolvem em direções opostas. Segundo demonstra o autor, nas unidades que adotam um modelo de intensificação, as referências aos mercados globais e às instituições externas se esvaecem, constituindose, para estas unidades uma realidade econômica personificada em relações econômicas, sociais e culturais da reprodução autônoma historicamente garantida, em que relações de reciprocidade e uma espécie de "economia moral” (Scott, 1976) são elementos centrais da lógica reprodutiva. Reproduzem-se, em virtude de aspectos como a auto-suficiência da família, o empenho no trabalho, o conhecimento prático associado à perícia e ao controle da complexidade inerente ao processo produtivo, mas também por conta das múltiplas redes sociais de reciprocidade que são capazes de sustentar (Sabourin, 2006). Os resultados se refletem em curto prazo na geração de renda e, em longo prazo, na possibilidade de manutenção desta forma de produzir.

De outro modo, o alto nível de inserção mercantil e externalização que se constituem problemáticos e remotos à reprodução autônoma, são as bases da lógica de reprodução dependente do mercado, sendo, na verdade, uma vantagem aqui. A estrutura deste calculus é dada pela razão custo/benefício econômico e pela escala, em que o resultado esperado é a rentabilidade econômica. ${ }^{5}$ Nesta via, as unidades se desenvolvem geralmente em

4 "Cada estilo de agricultura contém um calculus: um mais ou menos explícito framework de conceitos interconectados com os quais se 'lê' a realidade empírica relevante (neste caso a unidade de produção e as relações nas quais está inserida) e 'traduz' em novas ações. Um calculus é, como foi, a coluna vertebral de uma estratégia particular. Isto é a 'gramática' do processo de tomada de decisão” (Ploeg, 2003).

5 Outra forma de conceber essa oposição está no que Ploeg denominou "artesanalidade" e "empresarialidade". Esta se refere "a capacidade de adaptar o controle do processo de produção à penetração de 


\section{4}

uma escala de ampliação relativa à extensificação. Neste caso, cada vez mais os meios de trabalho e o próprio trabalho apresentam-se como custos diretos, sendo que este se aliena do produtor e perde qualidade e suas características de artesanalidade. Do mesmo modo, a eficiência econômica prevalece sobre a eficiência técnica; os benefícios em curto prazo tornam-se mais relevantes que em longo prazo; o conceito de risco econômico apresentase mais evidente; a produção por objeto de trabalho diminui; o processo de tomada de decisão se altera e, por fim, cria-se uma necessidade inerente de adoção de tecnologias externas.

O grau com que os agricultores inserem-se em uma ou outra via e a multiplicidade de arranjos entre distintos domínios (das relações econômicas e institucionais, da família e comunidade local, da produção) formam múltiplos e complexos estilos de agricultura que refletem noções, experiências, idéias e compreensões compartilhadas pelos agricultores como a melhor maneira de conduzir sua unidade de produção. Já a pluralidade de estratégias das quais os agricultores lançam mão é, ao mesmo tempo, resultado e origem dos diferentes estilos. As estratégias modificam os processos de trabalho, os investimentos de capital, o ciclo produtivo e a reprodução do grupo familiar, criando alternativas que se refletem em dois sentidos antagônicos: aumento ou diminuição da inserção em determinados mercados. Os agricultores podem formatar estratégias de natureza produtiva - intensificadoras de trabalho; estratégias fundiárias relacionadas ao aumento da superfície agrícola útil; estratégias vinculadas ao trabalho em atividades não agrícolas; estratégias vinculadas ao acesso à tecnologia que possibilitam maior produtividade da terra e do trabalho, entre outras.

Em um sentido, pode-se elevar o grau de inserção aos mercados. O recurso à pluriatividade é um dos meios mais freqüentes e eficazes neste sentido. Contudo, trata-se de uma espécie de mercantilização diferencial que acontece associada a um novo estágio de integração, o qual se dá pela via do mercado de trabalho (Schneider, 2006). Esta mercantilização não está associada ao aumento da externalização das unidades de produção e seus efeitos não repercutem em perda de autonomia (Marsden, 1995).

Em outro sentido, pode-se optar por um processo de autonomização e des-mercantilização que possibilitam diminuir a dependência dos agricultores frente às obrigações impostas pelos mercados, bancos e comerciantes. Neste sentido, estratégias de internalização de recursos, produção para autoconsumo e agroecologia têm se mostrado alternativas importantes.

Porém, é necessário destacar que muitas estratégias ultrapassam a dimensão estritamente produtiva e, conforme demonstra Ellis $(2000 ; 1998)$, tornam-se alternativas de diversificação dos meios de vida rural (rural livelihood diversification), as quais geram ativos e capitais (físicos, naturais, sociais, humanos) que permitem multiplicar as formas de reprodução das unidades familiares. Esta diversificação apresenta-se como a base de emergência de diferentes estilos de agricultura, representando, de acordo com Ellis (1998), o "processo pelo qual as famílias rurais constroem um portfolio diverso de atividades e o suporte social potencial em seu esforço para sobreviver e para melhorar seu padrão de vida". Segundo o autor, esse processo é determinado por múltiplos fatores que

[...] podem ser conceitualmente distintos, mas são raramente separáveis na prática. Todos eles são mediados pelas instituições sociais, incluindo laços de comunidade e parentesco, direitos de propriedade e obrigações, e relações de gênero com o grupo doméstico. Além disso, eles são formados pela interação com o ambiente físico, e pelas mudanças econômicas ao longo do tempo, incluindo o impacto sobre oportunidade de ganhos de renda dos ajustes estruturais e políticas de liberalização (Ellis, 1998).

Configuram-se, então, "estratégias reativas" advindas da necessidade relacionada à vulnerabilidade econômica de algumas unidades familiares ou "estratégias adaptativas" que expressam um processo voluntário de escolhas pródiversificação dos meios de vida (Ellis, 2000). Neste sentido, novamente fazendo referência à pluriatividade, é importante perceber como esta pode representar uma estratégia de reação que permite à família acessar ativos notadamente renda - essenciais para fazer frente às suas necessidades de reprodução, ou uma estratégia de escolha que permite acessar recursos que conferem maior autonomia frente ao ambiente econômico instável e maior margem de manobra em face de crises e choques externos (Kinsela et al., 2000). 


\section{MerCANTILIZAÇÃO E ESTILOS DE AGRICULTURA}

Explorar as contradições e heterogeneidades das relações entre os agricultores e os mercados impõe recorrer a uma complexa dialética que impede o estabelecimento de associações lineares entre um determinado grau de mercantilização e um estilo de agricultura específico. Como demonstram Long \& Ploeg (1994), ainda que existam nítidas inter-relações entre estilos de agricultura e conjuntos específicos de relações sociais é impossível atribuir uma tendência unilinear na qual estilos emergem como efeitos diretos de causas particulares:

O desenvolvimento de unidades de produção altamente mercantilizadas não é condicionado somente pelas relações de mercado, mas também emerge imediatamente determinadas por estas relações. Assim que estilos específicos são enfim inseridos na lógica do mercado. Mas isto implica que os mercados sejam compreendidos como causas destes estilos específicos? E devem estes estilos ser compreendidos como produtos unilineares daqueles mercados? Evidentemente não é este o caso [...] (Long \& Ploeg, 1994).

Nas situações em que, por exemplo, a mercantilização reflete a inserção em mercados globais de commodities agrícolas é razoável imaginar que estes procuram subordinar os discursos e as práticas dos agricultores a sua gramática de relações sociais. Contudo, mesmo onde este processo apresenta-se intensamente desenvolvido, não conseguiu impor que a única alternativa esteja entre se adaptar ou desaparecer. Embora o capital coordene o ritmo e a direção da mercantilização, os agricultores jogam um papel ativo, ampliando, aprofundando, transformando e resistindo ao curso de uma inserção subordinada ao mercado. Estabelecem-se assim comportamentos diversos frente a condições relativamente homogêneas, a partir dos quais são estruturadas estratégias vis-à-vis os mercados e as demais instituições sociais com as quais estes atores se relacionam. Neste caso, pode-se referir que

[...] novos estilos de agricultura emergem da capacidade de resistência contida dentro da agricultura. Os agricultores usam a maleabilidade do processo de produção e o espaço de manobra contido nos mercados e tecnologia, para construir novas respostas congruentes para o projeto dominante de modernização (Ploeg, 2003).

Segundo Ploeg $(1990,2003)$, os mercados representam uma arena na qual várias posições, isto é, vários estilos de agricultura, são possíveis. Não obstante, via de regra dois caminhos distintos são trilhados, demonstrando a emergência do que foi denominada "reprodução relativamente autônoma" e "reprodução dependente do mercado":

Os estilos de agricultura, como eles podem atualmente ser mapeados, podem ser considerados como algumas das muitas respostas para o projeto da modernização (...). Alguns estilos primariamente representam a internalização do projeto de modernização (e são materialmente dependentes de sua continuação). Outros estilos, por outro lado, representam um distanciamento de, e uma desconstrução de toda limitação e controle impostos pelo projeto modernizador (Ploeg, 2003).

Em resumo, os agricultores assumem trajetórias diferenciadas que podem, em um sentido, levar à reprodução do modelo da modernização acentuando a especialização produtiva fundada em recursos externos, bem como a dependência às flutuações dos preços internacionais e custos de produção e transação e, em outro, articular um afastamento estratégico deste regime. Neste caso, pode-se operar uma desmercantilização que visa à diminuição da dependência das unidades produtivas aos mercados de insumos e fatores de produção, mas, de outro modo, também é possível desenvolver uma inserção a mercados que não necessariamente possuem efeitos corrosivos sobre a base autônoma de recursos das unidades familiares, uma vez que esta interação pode ocorrer em um nível diferenciado, por exemplo, com a integração a circuitos de venda direta ao consumidor ou a mercados de trabalho, como é o caso referido da pluriatividade.

\section{CONSIDERAÇÕES FINAIS}

Não há, neste trabalho, uma pretensão conclusiva. Antes, as considerações aqui apresentadas buscam contribuir na divulgação e interpretação de um referencial analítico praticamente desconhecido no Brasil, que pode contribuir em uma série de estudos empenhados em apreender a diversidade de formas sociais no meio rural.

De modo geral, procurou-se demonstrar como a mercantilização da agricultura configura um processo parcial e multideterminado relacionado à configuração de distintos estilos de agricultura, estes sendo referidos como expressões da capacidade dos agricultores de criarem estratégias de reprodução vis-à-vis as pressões exercidas pelos mercados. Ao mesmo tempo, teve-se o cuidado de demonstrar que não necessariamente a mercantilização representa um fator negativo ao desenvolvimento rural, uma 
vez que, dependendo do nível em que este processo se desenvolve, pode resultar em maior espaço de manobra para os agricultores criarem alternativas de diversificação dos seus meios de vida.

\section{REFERÊNCIAS BIBLIOGRÁFICAS}

ABRAMOVAY, R. Desenvolvimento e instituições: a importância da explicação histórica. In: ARBIX, G., ZILBOVICIUS, M.; ABRAMOVAY, R. Razões e ficções do desenvolvimento. São Paulo: UNESP/EDUSP, 2001, $374 \mathrm{p}$.

BERNSTEIN, H. Capitalism and Petty Commodity Production. Journal of Cultural and Social Practice, n.20, p.11-28, 1986.

. African Peasantries: a theoretical framework. Journal of Peasant Studies, v.6, n.4, p.420-444, 1979.

BUTTEL, F. H.; LARSON, O. F.; GILLESPIE, JR., G. W. The sociology of agriculture. New York: Greenwood Press, 1991.

CHAYANOV, A. La organización de la unidad económica campesina. Buenos Aires: Nueva Vision, 1974.

ELLIS, F. Rural livelihoods and diversity in developing countries. Oxford (UK): Oxford University Press, 2000.4p.

Household strategies and rural livelihood diversification. The Journal of Development Studies, v.35, n1, p.1-38, 1998.

FRIEDMANN, H. Simple commodity production and wage labour in the American plais. Journal of Peasant Studies, v.6, n.1, p.71-100, 1978.

World market, state, and family farm: social bases of household production in the era of wage labor. Comparative Studies in Society and History, v.20, n.4, p.545-586, 1978a.

HOWDEN, P.; VANCLAY, F. Mythologisation of farming styles in Australian broadacre cropping. Rural Sociology, v.65, n.2, p.109-125, 2000.
KINSELLA, J.; FLOOR DE JONG, S. W.; RENTING, H. Pluriactivity as a livelihood strategy in Iris farm Households and its role in Rural Development. Sociologia Ruralis, v.40, n.4, p.481-496, 2000.

LONG, N. Development sociology: actor perspectives. London: Routledge, 2001. 8p.

Commoditization: thesis and antithesis. In: LONG, N. et al. The commoditization debate: labour process, strategy and social network, Wageningen: Wageningen Agricultural University, 1986. p.1-25.

LONG, N.; PLOEG, J. D. van der. Heterogeneity, actor and structure: towards a reconstitution of the concept of structure. In: Booth, D. (ed.). Rethinking Social Development: Theory, Research and Practice. Harlow: Longman, 1994. p. 62-90.

LONG, N.; PLOEG, J. D. van der.; CURTIN, C. \& BOX The commoditization debate: labour process, strategy and social network. Wageningen: Wageningen Agricultural University, 1986.

MARSDEN, T. Beyond agriculture? Regulating the new spaces. Journal of Rural Studies, London, v.3, n.11, p.28596, 1995.

MARX, K. O capital: o processo global de acumulação capitalista. v.1, São Paulo: Difel, 1982.

NAVARRO, Z. Do mundo da roça ao mercado: mudanças recentes e o desenvolvimento agrário no Sul do Brasil. Brasília: NEAD, 2002. (Relatório de pesquisa).

PLOEG, J. D. van der. O modo de produção camponês revisitado. In: SCHNEIDER, Sergio. A diversidade da agricultura familiar. Porto Alegre: UFRGS, 2006. p.13-56.

The virtual farmer: past, present and future of the Dutch peasantry. Assen: Van Gorcum, 2003.137p.

- Styles of farming: an introductory note on concepts and methodology. In: PLOEG, J. D. van der; LONG, A. Born from within: practices and perspectives of endogenous rural development. Assen: Van Gorcum, 1994. p.7-30. 
Rural sociology and the new agrarian question: a perspective from the Netherlands. Sociologia ruralis. v.32, n.2. p. 240-246, 1993.

. El proceso de trabajo agrícola y la mercantilización. In: GUZMAN, E. S.; GONZÁLES DE MOLINA, M (eds.). Ecología, campesinato y historia. Madri: Las ediciones de la piqueta, 1992. p. 153-95.

Labor, markets, and agricultural production. Boulder/San Francisco/Oxford: Westview Press, 1990.

. New challenges in the sociology of rural development: a rejoinder to Peter Vandergest. Sociologia Ruralis, v.28, n.1, p.30-41, 1988.

POLANYI, K. A grande transformação: as origens da nossa época. Rio de Janeiro: Campus, 1980.7p.

SABOURIN, E. Práticas sociais, políticas públicas e valores humanos. In: SCHNEIDER, S. A diversidade da agricultura familiar. Porto Alegre: UFRGS, 2006. p.215-39.

SCHNEIDER, S. A pluriatividade no Brasil: proposta de tipologia e sugestão de políticas. In: Congresso da Sociedade Brasileira de Economia e Sociologia Rural, 44, Fortaleza. Anais... Fortaleza: SOBER, 2006.

. Da crise da sociologia rural à emergência da sociologia da agricultura: reflexões a partir da experiência norte-americana. Cadernos de Ciência e Tecnologia, Brasília, v.14, n.2, p.225-38, 1997.

SCOTT, A. M. Towards a rethinking of Petty Commodity Production. Journal of Cultural and Social Practice, n.20, p.93-105, 1986.

SCOTT, J. C. The Moral Economy of the Peasant: rebellion and subsistence in southeast Asia. New Haven: Yale University Press, 1976.

VANCLAY F, HOWDEN PF, MESITI L; GLYDE S. The social and intellectual construction of farming styles: testing Dutch ideas in Australian agriculture. Sociologia Ruralis, v.46, n.1, p.61-82, 2006.
VANDERGEEST, P. Commercialization and commoditization: a dialogue between perspectives. Sociologia Ruralis, v.25, n.3, p.7-29, 1988. 